\title{
is hypoalbuminemia a new biomarker in severe pneumonia associated with coronavirus disease 2019?
}

\author{
Yavuz Otal ${ }^{1}$, GAMZE AVCIOĞLU², and Fadime Gullu Haydar ${ }^{1}$ \\ ${ }^{1}$ Ankara City Hospital \\ ${ }^{2}$ Affiliation not available
}

February 19, 2021

\begin{abstract}
Objective: In the present study, the importance of albumin level in severe pneumonia due to covid 19 was investigated. Design: This was a retrospective study. Setting:Emergency Department of Ankara City Hospital, between 1 september 2020 and 1 february May 2021. Subjects: Effective triage and early detection are very important for the control and treatment of coronavirus disease 2019. For this purpose the relation between hypoalbuminemia and other acute phase reactants was compared in severe pneumonia due to Covid-19. Main outcome measures: The data of 122 patients diagnosed with pneumonia due to Covid 19 and 60 healthy control group were retrospectively analyzed in statistical terms in computer medium. The cases were divided into 3 groups as Healthy Control Group, Intubated Group, and Non-Intubated Group. The lung tomography of patients diagnosed with Covid 19 pneumonia was examined one-by-one. The RT-PCR (Real-Time Polymerized Chance Reaction) test results were recorded from the system. The albumin, WBC (White Blood Cell), N/L (Neutrophil/Lymphocyte Ratio), CRP (C-Reactive Protein) levels, who are acute phase reactant levels, of the patients were compared with the Control Group. Also, the two groups who were intubated and not intubated were also compared. Results: When all the data were examined, it was found that the albumin levels were lower at statistically significant levels in all 3 study groups ( $p<0.01)$. The other acute phase reactants, N/L ratio and CRP levels were significantly higher $(\mathrm{p}<0.05)$. Hypoalbuminemia was found to be significantly lower as a result of the comparisons of the two groups that were intubated and not intubated $(\mathrm{p}=0.02)$, and no differences were detected in terms of other parameters $(\mathrm{p}>0.05)$. Conclusion: Serum albumin levels may be lower in severe Covid 19 pneumonia. Hypoalbuminemia can be a biomarker indicating the severity of the disease as an acute phase reactant.
\end{abstract}

\section{Hosted file}

Yavuz OTAL - ENG1.doc available at https://authorea.com/users/396703/articles/509812-ishypoalbuminemia-a-new-biomarker-in-severe-pneumonia-associated-with-coronavirus-disease2019

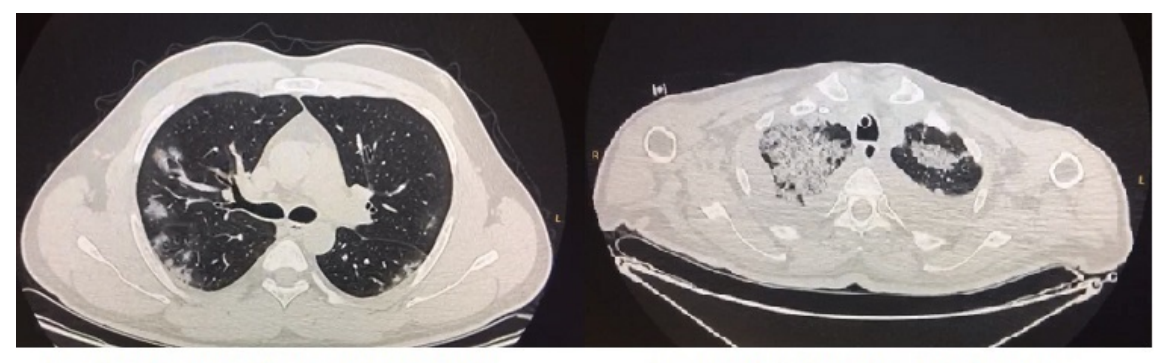

CT image of patient with non entubated covid 19

CT image of patient with entubated covid 19 

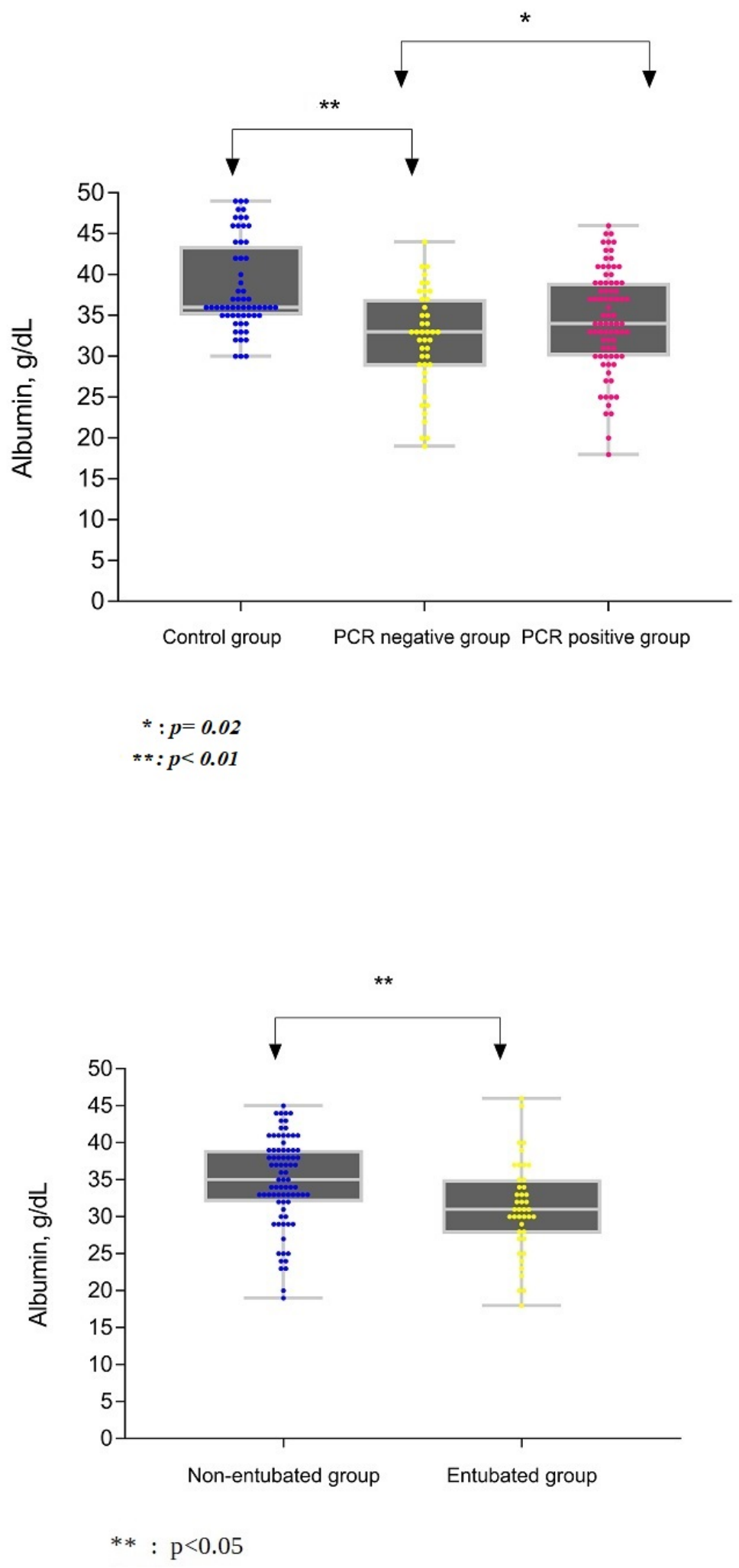


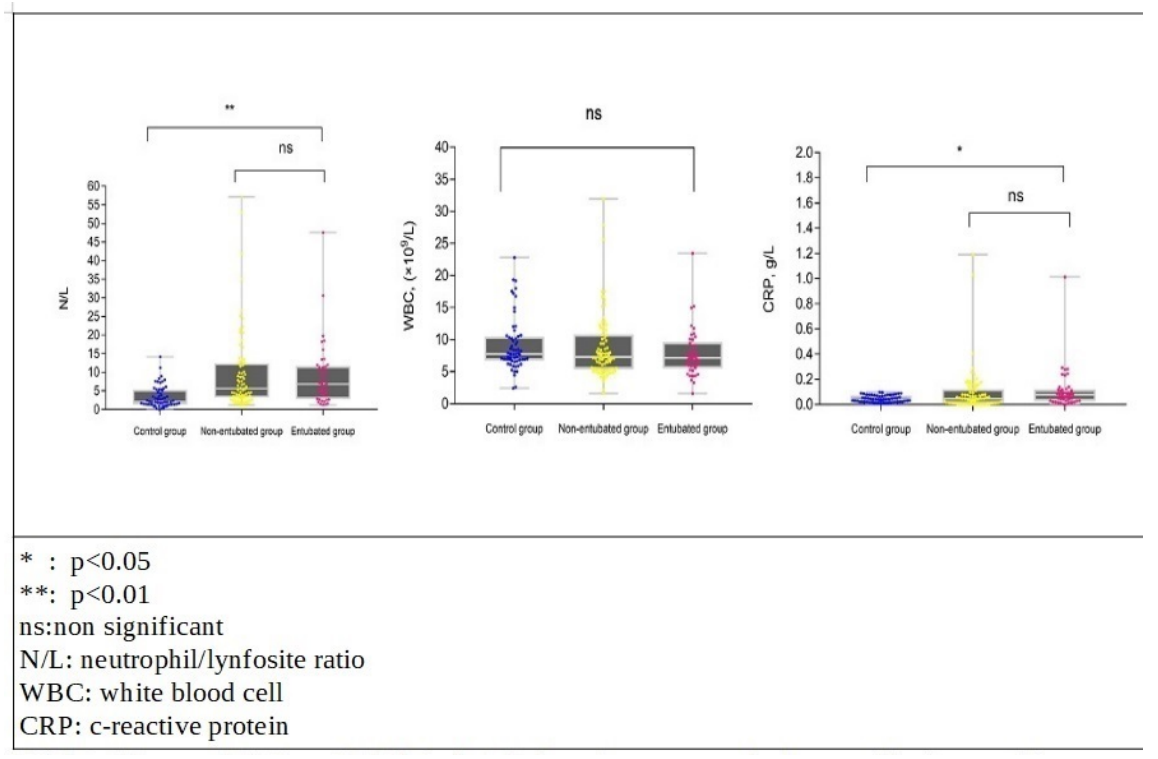

\section{Hosted file}

table1. doc available at https://authorea.com/users/396703/articles/509812-is-hypoalbuminemiaa-new-biomarker-in-severe-pneumonia-associated-with-coronavirus-disease-2019 